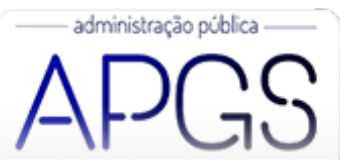

Administração Pública e Gestão Social ISSN: 2175-5787

apgs@ufv.br

Universidade Federal de Viçosa

Brasil

\title{
Eficiência e produtividade nos Institutos Federais de Educação, Ciência e Tecnologia do Brasil
}

Nobre Parente, Paulo Henrique; de Maria, Camila Carol; Severiano Dutra, Rogério; Paulo, Edilson Eficiência e produtividade nos Institutos Federais de Educação, Ciência e Tecnologia do Brasil

Administração Pública e Gestão Social, vol. 13, núm. 1, 2021

Universidade Federal de Viçosa, Brasil

Disponible en: http://www.redalyc.org/articulo.oa?id=351564966006

\section{(c) $(1) \Theta \theta$}

Esta obra está bajo una Licencia Creative Commons Atribución-NoComercial-SinDerivar 3.0 Internacional. 


\title{
Eficiência e produtividade nos Institutos Federais de Educação, Ciência e Tecnologia do Brasil
}

\author{
Efficiency and productivity in the Federal Institutes of Education, Science and Technology of Brazil \\ Eficiencia y productividad en los Institutos Federales de Educación, Ciencia y Tecnología de Brasil
}

Paulo Henrique Nobre Parente

Redalyc: http://www.redalyc.org/articulo.oa?

Universidade Federal do Ceará., Brasil id $=351564966006$

paulonobreparente@gmail.com

Camila Carol de Maria

Instituto Federal de Educação, Ciência e Tecnologia do

Ceará, Brasil

camilacarolns@gmail.com

Rogério Severiano Dutra

Instituto Federal de Educação, Ciência e Tecnologia do

Ceará., Brasil

dutra.contabil@yahoo.com.br

Edilson Paulo

Universidade Federal do Rio Grande do Sul, Brasil

prof.edilson.paulo@gmail.com

Recepción: 29 Julio 2019

Aprobación: 21 Octubre 2019

Publicación: 01 Enero 2021

\section{Resumo:}

Objetivo da pesquisa: Este artigo analisa a evolução da eficiência e da produtividade dos gastos públicos nos Institutos Federais de Educação, Ciência e Tecnologia (IFs) do Brasil no período entre 2010 e 2017, que incorpora o processo de expansão da rede federal. Enquadramento teórico: Este artigo fundamenta-se na literatura da teoria de fronteira, que se baseia em modelos matemáticos não paramétricos para avaliar a eficiência de unidades de produção educacionais.

Metodologia: A amostra é composta por 263 observações, representativa aos 38 IFs, distribuídas em um painel desbalanceado. O método de análise envoltória de dados (DEA) e o índice de produtividade de Malmquist (IPM) foram empregados, respectivamente, para mensurar os escores de eficiência e de produtividade.

Resultados: Os resultados demonstram que, ao longo do processo de expansão da rede federal, os IFs apresentaram ganhos de eficiência e de produtividade, apresentando um incremento médio de 13,7\%, apesar de parte da literatura corroborar que, durante os processos de expansão de sistemas educacionais, a eficiência e a qualidade do ensino apresentem um comportamento retrativo. Originalidade: Este estudo diferencia-se dos demais ao analisar a eficiência e produtividade em instituições de educação profissional, científica e tecnológica (EPCT), lacuna ainda presente nos estudos nacionais. Investiga também a evolução dos escores de eficiência e de produtividade ao longo do processo de expansão da rede federal.

Contribuiçóes teóricas e práticas: Este estudo contribui para a literatura ao passo que investiga a evolução da eficiência e da produtividade nos IFs, que apresentam diversas particularidades - verticalização de ensino, seleção de alunos estrutura multicampi, tripé ensino-pesquisa-extensão - quando comparadas com as demais instituições. Sob a perspectiva de gestão de instituições de EPCT, este estudo identifica as instituições eficientes, avaliando as práticas de gestão de produtos e (ou) insumos dos gestores públicos educacionais.

Palavras-Chave: finanças públicas, gastos públicos, ensino profissional e tecnológico, análise envoltória de dados, índice de produtividade de Malmquist.

\section{Abstract:}


Research purpose: This article analyzes the evolution of efficiency and productivity of public spending in the Federal Institutes of Education for Science and Technology (IFs) in Brazil in the period between 2010 and 2017, which incorporates the process of expansion of the federal network.

Theoretical framework: This article is based on the frontier theory literature, which is based on nonparametric mathematical models to assess the efficiency of educational production units.

Methodology: The sample consists of 263 observations, representative of the 38 IFs, distributed in an unbalanced panel. The data envelopment analysis method (DEA) and the Malmquist productivity index (IPM) were used, respectively, to measure the efficiency and productivity scores.

Results: The results demonstrate that, throughout the process of expansion of the federal network, the IFs showed gains in efficiency and productivity, presenting an average increase of $13.7 \%$, although part of the literature corroborates that, during the systems expansion processes educational institutions, the efficiency and quality of teaching exhibit a retractive behavior.

Originality: This study differs from the others when analyzing efficiency and productivity in educational, professional, scientific and technological (EPCT) institutions, a gap still presents in national studies. It also investigates the evolution of the efficiency and productivity scores throughout the expansion process of the federal network.

Theoretical and practical contributions: This study contributes to the literature while investigating the evolution of efficiency and productivity in the IFs, which presents several particularities - verticalization of teaching, selection of students with a multicampi structure, teaching-research-extension tripod - when compared to other institutions. From the perspective of management of EPCT institutions, this study identifies efficient institutions, evaluating the output/input management practices of public educational managers.

KEYWORDS: public finances, public spending, vocational and technological education, data envelopment analysis, Malmquist productivity index.

\section{RESUMEN:}

Objetivo de la investigación: Este artículo analiza la evolución de la eficiencia y productividad del gasto público en los Institutos Federales de Educación, Ciencia y Tecnología (IFs) de Brasil en el período de 2010 hasta 2017, que incorpora el proceso de expansión de la red federal.

Marco teórico: Este artículo se basa en la literatura sobre teoría de límites, que se basa en modelos matemáticos no paramétricos para evaluar la eficiencia de las unidades de producción educativa.

Metodología: La muestra consta de 263 observaciones, representativas de las 38 IFs, distribuidas en un panel desbalanceado. Se utilizó el método de análisis envolvente de datos (DEA) y el índice de productividad de Malmquist (IPM), respectivamente, para medir los puntajes de eficiencia y productividad.

Resultados: Los resultados demuestran que, a lo largo del proceso de expansión de la red federal, los IFs mostraron ganancias en eficiencia y productividad, presentando un incremento promedio de $13.7 \%$, aunque parte de la literatura corrobora que, durante los procesos de expansión de sistemas Las instituciones educativas, la eficiencia y calidad de la enseñanza exhiben un comportamiento retráctil.

Originalidad: Este estudio se diferencia de los demás al analizar la eficiencia y la productividad en las instituciones de educación profesional, científica y tecnológica (EPCT), una brecha aún presente en los estudios nacionales. Además, investiga la evolución de los puntajes de eficiencia y productividad a lo largo del proceso de expansión de la red federal.

Contribuciones teóricas y prácticas: Este estudio aporta a la literatura al mismo tiempo que investiga la evolución de la eficiencia y productividad en los IFs, que presentan varias particularidades - verticalización de la docencia, selección de estudiantes con estructura multicampi, trípode docencia-investigación-extensión - en comparación con otras instituciones. Desde la perspectiva de la gestión de las instituciones EPCT, este estudio identifica instituciones eficientes, evaluando las prácticas de gestión de productos e (o) insumos de los gestores educativos públicos.

Palabras Clave: las finanzas públicas, gastos públicos, enseñanza profesional y tecnológica, análisis de datos, índice de productividad de Malmquist.

\section{INTRODUÇÃO}

A literatura reconhece os investimentos em educação como fator determinante para o desenvolvimento de uma nação (Magalhães, Silveira, Abrantes, Ferreira, \& Wakim, 2010; Zoghbi, Matos, Rocha, \& Arvate, 2009). Contudo, o aumento dos gastos públicos não representa, necessariamente, ampliação da qualidade da educação de um país (Rosano-Peña, Albuquerque, \& Daher, 2012), mas, de fato, a forma como esses gastos 
são realizados (Agasisti, 2014; Gramani, 2017; Hanushek \& Luque, 2003; Moreira, Cunha, Ferreira, \& Silveira, 2011). Esta conjuntura remete à necessidade de a gestão pública atuar de forma eficiente e produtiva.

Diversas pesquisas foram desenvolvidas com a finalidade de identificar o nível de eficiência em instituições educacionais em diferentes níveis de ensino (Castro \& Sousa, 2018; Costa, Sousa, Souza, \& Silva, 2012; Costa, Ferreira, Braga, \& Abrantes, 2015; Kaveski, Martins, \& Scarpin, 2015; Lourenço, Angotti, Nascimento, \& Sauerbronn, 2017; Moreira et al., 2011). Com menor intensidade, outros estudos foram realizados no contexto das escolas técnicas (Furtado \& Campos, 2015) e militares (Silva, Pereira, Dantas, \& Araújo, 2016). A proposta deste estudo consiste em analisar a eficiência nos Institutos Federais de Educação, Ciência e Tecnologia (IFs).

O processo de expansão da rede federal de Educação Profissional, Científica e Tecnológica (EPCT) no Brasil, iniciado em 2008 (Lei n. 11892, 2008), elevou o quantitativo de regióes atendidas, alcançando, em 2016, um total de 659 instituições de ensino profissional e tecnológico (Portaria MEC n. 378, 2016). Como consequência, o crescimento da oferta de vagas gerou uma ampliação na quantidade de recursos dispendidos na referida rede. Entretanto, o aumento nos níveis de investimento não se traduz, necessariamente, em aumento da qualidade na educação (Rosano-Peña et al., 2012).

Nesse sentido, alguns autores defendem que, em qualquer processo de expansão do ensino, a qualidade do sistema educacional tende a decrescer (Castro \& Sousa, 2018; Gusmão, 2013; Marchelli, 2010). A adesão aos programas de expansão da educação pode gerar a perda de expectativa relacionada à qualidade do ensino (Cavalcante \& Andriola, 2012). Especificamente, a expansão do ensino pode reduzir a proficiência dos alunos (Marchelli, 2010), aumentar a necessidade de formação docente (Krawczyk, 2013), majorar a necessidade de manutenção em termos de infraestrutura e de gestão escolar (Furtado \& Campos, 2015), buscando garantir a sustentabilidade do sistema de ensino, inclusive no EPCT, por exemplo. Considerando o exposto, este trabalho tem o objetivo de analisar a evolução da eficiência e da produtividade dos gastos públicos em educação nas instituições federais brasileiras de EPCT no período entre 2010 e 2017.

Para tanto, aplicamos a técnica Análise Envoltória de Dados (DEA, do inglês Data Envelopment Analysis), utilizando os modelos de retornos variáveis (BCC) e constantes (CCR) de escala, ambos com orientação para outputs, a fim de mensurar a eficiência técnica e de escala. Foi calculado o índice de Malmquist para identificar a variação da produtividade do nível de eficiência. As metodologias empregadas visam testar a hipótese de que os níveis de produtividade e de eficiência das instituições de EPCT do Brasil decresceram ao longo do processo de expansão da rede federal.

A eficiência dos gastos públicos em educação foi investigada em diferentes níveis e modalidades de ensino, todavia, a análise em instituições de EPCT ainda é escassa. Além disso, este estudo avança na literatura, pois: (i) realiza uma análise dinâmica em que é incluída a dimensão temporal na análise de eficiência, ao combinar o modelo DEA com a análise do índice de produtividade de Malmquist; e (ii) investiga a eficiência ao longo do período de expansão da rede federal de EPCT. Parece ser relevante identificar se os recursos públicos estão sendo empregados de forma eficiente a partir da política de expansão da rede federal de EPCT, considerando a finalidade de proporcionar o desenvolvimento socioeconômico de uma nação a partir dos investimentos em educação (Magalhães et al., 2010).

O resultado deste estudo pode contribuir para a literatura, uma vez que há uma lacuna de pesquisa sobre eficiência e produtividade nas instituições de EPCT. O resultado do levantamento bibliográfico, apresentado na Tabela 1, dispóe que a literatura tem dado ênfase ao estudo da eficiência em escolas das redes municipais e estaduais. As instituições de EPCT apresentam particularidades quando comparadas com essas instituições ensino, como, por exemplo, a amplitude das modalidades de ensino dos cursos ofertados (médio, técnico, superior e pós-graduação), o processo seletivo de candidatos, a interiorização das instituições (multicampi) e os pilares atendidos (ensino, pesquisa e extensão). Essa complexidade pode, embora não seja analisada neste estudo, afetar a gestão dos recursos e, de forma consequente, os resultados obtidos por estas instituições. 
Como contribuição prática, este estudo pode permitir aos gestores dos IFs identificar as instituições consideradas eficientes, avaliando as práticas de gestão de produtos e insumos dos gestores públicos educacionais. Sendo assim, os achados deste trabalho podem levar a explicação acerca dos resultados direcionados aos discentes, a partir da utilização dos recursos direcionados à educação e à relevância encontrada nas políticas, objetivando a qualidade do ensino (Hanushek \& Luque, 2003).

\section{REVISÃO DE LITERATURA}

\subsection{Eficiência em instituições educacionais e hipótese}

A literatura reconhece os investimentos em educação como fator-chave no desenvolvimento social e econômico de um país (Magalhães et al., 2010), sendo considerado, inclusive, o gasto mais significativo, quando comparado com os demais (Zoghbi et al., 2009). No entanto, o aumento nos níveis de investimento não se traduz, necessariamente, em aumento da qualidade na educação (Rosano-Peña et al., 2012).

Esta linha de pensamento emergiu a partir do Relatório de Coleman, em 1966, em que um dos tópicoschave discutidos foi que, dentro do processo educacional, os recursos explicam apenas pequenas variações do desempenho escolar. O baixo poder explicativo do investimento no desempenho educacional pode estar associado ao modo como esses gastos são realizados. Essa perspectiva remete à necessidade de o gestor público considerar a eficiência e a produtividade no processo decisório.

Enquanto que a eficiência é um conceito relativo, que compara a produtividade entre as unidades tomadoras de decisão (DMUs, do inglês Decision Making Units), a produtividade é representada pela razão entre produto e insumo e indica o nível de aproveitamento de recursos utilizados no processo produtivo (Rosano-Peña et al., 2012). Para este estudo, eficiência do gasto público compreende como os melhores resultados referentes a um dado nível de gasto (Zoghbi et al., 2009). Dito de outra forma, eficiência é um conceito que mede performance, uma vez que mede a relação entre o produto, considerando a disponibilidade limitada de recursos, e o que poderia ter sido produzido com a mesma quantidade de recursos (Nascimento, Nossa, Bernardes, \& Sousa, 2015). Para estimar esses índices de eficiência na educação, os estudos têm empregado técnicas não paramétricas - quando não há um modelo funcional pré-estabelecido e os parâmetros precisam ser descobertos - destacando-se a Análise Envoltória de Dados (DEA).

A técnica DEA foi introduzida inicialmente por Charnes, Cooper e Rhodes (1978) e definida para uma análise de eficiência com retornos constantes de escala (CCR). Posteriormente, o modelo foi estendido por Banker, Charnes e Cooper (1984), que inclui o pressuposto de retornos variáveis de escala (BCC). Enquanto o modelo CCR gera uma fronteira de eficiência, em que qualquer variação nas entradas (inputs) produz uma variação proporcional nas saídas (outputs), o modelo BCC substitui o axioma da proporcionalidade pela convexidade entre inputs e outputs.

Destaca-se que os modelos podem proporcionar níveis de eficiência divergentes para uma mesma DMU. Segundo Gresele e Krukoski (2018), a eficiência de escala é determinada pela razão entre a eficiência do modelo CCR e a eficiência do modelo BCC. Além da determinação dos modelos CCR e BCC, há ainda a escolha da orientação dos mesmos para insumos (inputs) ou para produtos (outputs).

Normalmente, as pesquisas sobre eficiência em educação utilizam a técnica DEA, com o emprego do modelo de retornos variáveis de escala (BCC), com orientação para os produtos. Isso ocorre, pois, partindo da premissa de escassez de recursos no setor público, busca-se maximizar os resultados em razão do orçamento limitado (Costa \& Castanhar, 2003), além de considerar que a relação entre insumo e produto não é necessariamente proporcional (Cavalcante \& Andriola, 2012).

De forma comparativa, outros autores defendem que uma análise orientada para os insumos pode ser relevante, quando se pretende obter resultados destinados a identificar o quanto de recurso público pode ser 
reduzido, mantendo os mesmos produtos educacionais (Castro \& Sousa, 2018). Outras extensões do modelo são empregadas para estimar, por exemplo, a eficiência produtiva pura, as mudanças tecnológicas e a evolução da produtividade, através do índice de Malmquist (Costa et al., 2015; Rosano-Peña et al., 2012).

Nesse contexto, convém destacar o desenvolvimento de políticas para a ampliação das instituições de EPCT, que emergiram para atender às necessidades técnicas e tecnológicas locais através de uma educação verticalizada (Furtado \& Campos, 2015). No Brasil, essas instituições passaram por diversas reestruturações e, em 2008, foram formalmente institucionalizadas sob a denominação de Rede Federal de Educação Profissional, Científica e Tecnológica (Lei n. 11892, 2008).

O crescimento da rede de EPCT tem por consequência imediata o aumento da utilização de recursos financeiros e a ampliação da oferta de vagas, demandando uma administração eficiente por parte dos gestores públicos. Todavia, alguns estudos indicam uma associação negativa entre a expansão e a qualidade do sistema de educacional (Castro \& Sousa, 2018; Gusmão, 2013, Marchelli, 2010).

A aplicação de recursos na educação, quando realizada de forma aleatória, pode ter como consequência a perda de eficiência nos resultados, além de provocar problemas de continuidade da instituição. Entende-se por decisões de investimento aleatórias aquelas que são realizadas sem o devido planejamento dos recursos. Nesse sentido, a adesão de programas de expansão possibilita a perda de expectativa relacionada à qualidade do ensino (Cavalcante \& Andriola, 2012), gerando a perspectiva de que o aumento de recursos financeiros e de oferta de vagas gere efeito inverso na qualidade da educação.

A expansão do ensino produz, de certa forma, uma queda na proficiência dos alunos, pois aumentando a quantidade de vagas, aumenta, por consequência, a competição e a distribuição de recursos (Marchelli, 2010). A expansão do ensino traz consigo grandes desafios como, por exemplo, os conteúdos a serem ministrados, a formação e a remuneração dos docentes, as condições de infraestrutura e da gestão da instituição educacional (Krawczyk, 2013).

A Rede Federal de EPCT apresenta especificidades estratégicas e organizacionais, quando comparada com as demais instituições de ensino. Por sua vez, está distribuída em estruturas multicampi, oferece o ensino verticalizado e apresenta articulação entre ensino, pesquisa e extensão (Furtado \& Campos, 2015). De tal modo, a decisão de alocação dos recursos pode ser afetada pela complexidade institucional, implicando em perdas residuais de eficiência educacional.

Combinados, os argumentos precedentes sugerem que a expansão e a complexidade da instituição educacional podem estar associadas à eficiência, levando-nos à seguinte hipótese de pesquisa: os níveis de produtividade e de eficiência das instituições de EPCT do Brasil decresceram ao longo do processo de expansão da rede federal.

\subsection{Estudos empíricos recentes e lacuna de pesquisa}

Pesquisas foram desenvolvidas para avaliar a eficiência técnica dos gastos públicos nas diferentes funções do governo, especialmente na prestação de serviços públicos essenciais (saúde, educação e habitação). Nesta pesquisa, a análise limita-se à eficiência dos gastos com educação nos Institutos Federais de Educação, Ciência e Tecnologia (IFs) do Brasil.

Dentre as metodologias disponíveis, a literatura brasileira tem utilizado o método de Análise Envoltória de Dados (em inglês, Data Envelopment Analysis - DEA) para mensurar a eficiência dos gastos públicos em educação (ver Quadro 1). Os métodos FreeDisposal Hull (FDH) e StochasticFrontier Analysis (SFA) também mensuram a eficiência, contudo, são empregados com menor frequência.

Para a grande maioria dos estudos, os autores evidenciaram baixos níveis de eficiência nos gastos públicos em educação, encontrados, quase em sua totalidade, através da DEA. Em contraponto, o Governo Federal tem majorado, significativamente, os investimentos públicos em educação. Por exemplo, em relação ao Produto Interno Bruto (PIB), os gastos totais em educação cresceram 34,8\% entre 2000 e 2013 (Portaria 
MEC n. 378, 2016). Esses resultados parecem indicar que a relação entre investimento e eficiência na educação não é direta, conforme sugere Rosano-Peña et al. (2012).

Parte representativa dessas pesquisas foi desenvolvida em contexto municipal, utilizando medidas financeiras para os inputs e medidas de avaliação institucional para os outputs. Essa conjuntura sugere que mais pesquisas sejam realizadas em instituições públicas federais de educação, bem como direciona ao uso de métricas gerenciais. Nesse contexto, Gupta e Verhoeven (2001) defendem que o desempenho na educação deve ser avaliado em termos de acesso, conclusão da escolaridade e nível de aproveitamento.

Convém destacar o trabalho desenvolvido por Furtado e Campos (2015), que analisa a eficiência técnica dos gastos em educação de 19 IFs do Brasil, entre 2012 e 2013. A fim de expandir os resultados sobre o tema nesse contexto, analisamos os dados de uma amostra composta por 38 IFs no período entre 2010 e 2017 (Lei n. 11892, 2008), identificando, adicionalmente, a evolução do nível de produtividade dessas instituições. 


\section{Quadro 1 - Eficiência dos gastos públicos em educação}

\begin{tabular}{|c|c|c|c|c|}
\hline Autores & $\begin{array}{l}\text { Amostra } \\
\text { [periodo] }\end{array}$ & Input e [output] & Principais resultados & $\begin{array}{l}\text { Método } \\
\text { (modelo) } \\
\text { [orientação] }\end{array}$ \\
\hline $\begin{array}{l}\text { Cuéllar } \\
\text { (2014) }\end{array}$ & $\begin{array}{l}15 \text { países da } \\
\text { América Latina } \\
\text { [2000-2009] }\end{array}$ & $\begin{array}{l}\text { Gasto por aluno, relação } \\
\text { professor jaluno [taxa de } \\
\text { alfabetização, de matrícula e de } \\
\text { conclusão, resultado no PISA] }\end{array}$ & $\begin{array}{l}\text { Os paises ineficientes poderiam aumentar } \\
\text { entre } 3,0 \% \text { e } 11,0 \% \text { os resultados com o mesmo } \\
\text { gasto público. }\end{array}$ & $\begin{array}{l}\text { DEA e FDH } \\
\text { [output] }\end{array}$ \\
\hline $\begin{array}{l}\text { Diel, Diel, } \\
\text { Schulz, } \\
\text { Chiarello e } \\
\text { Rosa (2014) }\end{array}$ & $\begin{array}{l}268 \text { cidades com } \\
\text { população acima } \\
\text { de } 100 \text { mil } \\
\text { habitantes [2010] }\end{array}$ & $\begin{array}{l}\text { Gastos com educação } \\
\text { [matriculas/habitantes } n^{\circ} \text { de } \\
\text { docentes, } n^{\circ} \text { de escolas, média de } \\
\text { notas escolares] }\end{array}$ & $\begin{array}{l}\text { Do total de cidades, apenas sete }(2,6 \%) \\
\text { apresentaram nivel de eficiência máximo. As } \\
\text { cidades com maiores niveis de eficiências estão } \\
\text { localizadas nas capitais brasileiras. }\end{array}$ & $\begin{array}{l}\text { DEA (CCR) } \\
\text { [output] }\end{array}$ \\
\hline $\begin{array}{l}\text { Costa et al. } \\
(2015)\end{array}$ & $\begin{array}{l}831 \text { municipios } \\
\text { do Estado de } \\
\text { Minas Gerais } \\
\text { [2006-2009] }\end{array}$ & $\begin{array}{l}\text { Gasto per capita com educação, valor } \\
\text { adicionado fiscal per capita [Taxa de } \\
\text { matrícula, indice de qualidade da } \\
\text { educação] }\end{array}$ & $\begin{array}{l}\text { Municipios com melhores condições } \\
\text { socioeconômicas apresentaram melhor nivel de } \\
\text { eficiência, que inclui a dimensão educação. }\end{array}$ & $\begin{array}{l}\text { DEA (CCR) } \\
\text { [output] }\end{array}$ \\
\hline $\begin{array}{l}\text { Furtado e } \\
\text { Campos } \\
\text { (2015) }\end{array}$ & $\begin{array}{l}19 \text { institutos } \\
\text { federais } \\
\text { brasileiros [2012- } \\
2013]\end{array}$ & $\begin{array}{l}\text { Gasto corrente por aluno, indice de } \\
\text { titulação do corpo docente, relação } \\
\text { aluno/docente [relação } \\
\text { concluinte/matriculado] }\end{array}$ & $\begin{array}{l}\text { Apenas } 31,0 \% \text { dos institutos federais atingiram } \\
\text { o escore de eficiência máximo, em razâo da } \\
\text { maior quantitativo de concluintes e do menor } \\
\text { gasto por aluno. }\end{array}$ & $\begin{array}{l}\text { DEA (BCC) } \\
\text { [output] }\end{array}$ \\
\hline $\begin{array}{l}\text { Magro e Silva } \\
(2016)\end{array}$ & $\begin{array}{l}26 \text { capitais } \\
\text { brasileiras [2005, } \\
2007,2009 \\
2011 \text { e } 2013]\end{array}$ & $\begin{array}{l}\text { Gasto com educação, indice da LRF } \\
\text { (Gasto em educaçăo/arrecadação + } \\
\text { transferências) [n }{ }^{\circ} \text { de matrículas, } n^{\circ} \\
\text { de professores, } n^{\circ} \text { de escolas, } \\
\text { resultado no IDEB, PIB] }\end{array}$ & $\begin{array}{l}\text { O maior investimento em educação implica em } \\
\text { melhores resultados no IDEB, melhor } \\
\text { desempenho do PIB e maior número de } \\
\text { escolas. }\end{array}$ & $\begin{array}{l}\text { DEA (BCC) } \\
\text { [input] }\end{array}$ \\
\hline $\begin{array}{l}\text { Amorim, } \\
\text { Diniz e Lima } \\
\text { (2017) }\end{array}$ & $\begin{array}{l}223 \text { municipios } \\
\text { do Estado da } \\
\text { Paraíba [2009- } \\
\text { 2011] }\end{array}$ & $\begin{array}{l}\text { Despesa corrente por aluno } \\
\text { [resultado na Prova Brasil] }\end{array}$ & $\begin{array}{l}\text { Os municípios alcançaram em média } 77,6 \% \text { de } \\
\text { eficiência dos gastos públicos municipais em } \\
\text { educação. }\end{array}$ & $\begin{array}{l}\text { DEA-S (BCC) } \\
\text { [output] }\end{array}$ \\
\hline $\begin{array}{l}\text { Begnini e } \\
\text { Tosta (2017) }\end{array}$ & $\begin{array}{l}26 \text { estados } \\
\text { brasileiros e } \\
\text { Distrito Federal } \\
\text { [2011] }\end{array}$ & $\begin{array}{l}\text { Gasto por aluno, funções docentes, } \\
\text { número de estabelecimentos } \\
\text { [resultado no IDEB] }\end{array}$ & $\begin{array}{l}\text { Cerca de } 26,0 \% \text { dos estados brasileiros } \\
\text { apresentaram gastos eficientes. O estado do } \\
\text { Piauí apresentou o pior nivel de eficiência. }\end{array}$ & $\begin{array}{l}\text { DEA (CCR) } \\
\text { [output] }\end{array}$ \\
\hline $\begin{array}{l}\text { Monte e } \\
\text { Leopoldino } \\
\text { (2017) }\end{array}$ & $\begin{array}{l}176 \text { municipios } \\
\text { cearenses [2015] }\end{array}$ & Gasto por aluno [Resultado no IDEB] & $\begin{array}{l}\text { Cerca de } 77,0 \% \text { das DMUs atingiram indices de } \\
\text { ineficiência moderada. }\end{array}$ & $\begin{array}{l}\text { DEA (BCC) } \\
\text { [output] }\end{array}$ \\
\hline $\begin{array}{l}\text { Schuster e } \\
\text { Zonatto } \\
\text { (2017) }\end{array}$ & $\begin{array}{l}258 \text { municípios } \\
\text { brasileiros [2013] }\end{array}$ & $\begin{array}{l}\text { Despesas liquidadas, gasto médio, } \\
\text { IDHM educaçấo, IDHM renda } \\
\text { [Resultado médio no IDEB] }\end{array}$ & $\begin{array}{l}\text { Os municipios com maior custo por aluno e } \\
\text { localizados em regiôes com maior nivel de } \\
\text { desenvolvimento econômico apresentam-se } \\
\text { menos eficientes. }\end{array}$ & $\begin{array}{l}\text { DEA (BCC) } \\
\text { [output] }\end{array}$ \\
\hline $\begin{array}{l}\text { Castro e } \\
\text { Sousa (2018) }\end{array}$ & $\begin{array}{l}149 \text { municipios } \\
\text { cearenses [2011] }\end{array}$ & $\begin{array}{l}\text { Gasto por aluno, [relação } \\
\text { professor /aluno, número de salas e } \\
\text { estabelecimentos /alunos] }\end{array}$ & $\begin{array}{l}\text { Os municípios cearenses podem diminuir, em } \\
\text { média, os gastos entre } 46,0 \% \text { e } 53,0 \% \text {, sem } \\
\text { reduzir a produção educacional dos } \\
\text { municípios. }\end{array}$ & $\begin{array}{l}\text { DEA } \\
\text { (BCC/CCR) } \\
\text { [input] }\end{array}$ \\
\hline $\begin{array}{l}\text { Firmino e } \\
\text { Leite (2018) }\end{array}$ & $\begin{array}{l}149 \text { municipios } \\
\text { paraibanos [2007 } \\
\text { e 2009] }\end{array}$ & $\begin{array}{l}\text { Recursos Fundeb, outras fontes de } \\
\text { recursos da educação básica } \\
\text { [Resultado no IDEB] }\end{array}$ & $\begin{array}{l}\text { Em média, } 9,1 \% \text { dos municípios são eficientes. } \\
\text { os resultados mostram um crescimento ín fimo } \\
\text { de } 0,7 \% \text { no periodo. }\end{array}$ & $\begin{array}{l}\text { DEA (BCC) } \\
\text { [output] }\end{array}$ \\
\hline $\begin{array}{l}\text { Gresele e } \\
\text { Krukoski } \\
(2018)\end{array}$ & $\begin{array}{l}389 \text { municipios } \\
\text { do Estado do } \\
\text { Paraná [2015] }\end{array}$ & $\begin{array}{l}\text { Investimento por aluno, } n^{\circ} \text { de } \\
\text { docentes por aluno, } n^{\circ} \text { de escolas por } \\
100 \text { alunos [Resultado no IDEB] }\end{array}$ & $\begin{array}{l}\text { Apenas } 3,3 \% \text { dos municipios atingiram os } \\
\text { escores máximos de eficiência. Os resultados } \\
\text { evidenciaram que há uma correlação negativa } \\
\text { entre os inputse a eficiência. }\end{array}$ & $\begin{array}{l}\text { DEA (BCC) } \\
\text { [input] }\end{array}$ \\
\hline
\end{tabular}


Fonte: Elaborado pelos autores.

Nota: Em razão da quantidade de estudos sobre a eficiência no contexto educacional ser expressiva, optamos por apresentar somente os estudos desenvolvidos nos últimos 5 (cinco) anos e publicados em revistas com estrato Qualis Periódico B2 ou superior (Quadriênio 2013-2016), sendo o termo principal pesquisa: "Eficiência do gasto público em educação". Os estudos, além de utilizar diferentes metodologias para calcular os escores de eficiência, também empregaram outras técnicas estatísticas, como, por exemplo, a análise de regressão (linear, logística e quantílica). A pesquisa foi realizada através do Google Scholar, utilizando os critério definidos nesta nota. Legenda: Análise Envoltória de Dados (Data Envelopment Analysis - DEA); Análise Envoltória de Dados Sequencial (DEA-S); Retornos Constantes de Escala - CCR (Constante Returns to Scale - CRS); Retornos Variáveis de Escala - BCC (Variable Returns to Scale - VRS); Sistema Nacional de Avaliação da Educação Básica (SAEB); Lei de Responsabilidade Fiscal (LRF); Índice de Desenvolvimento Humano Municipal (IDHM); Produto Interno Bruto (PIB).

Esses estudos se concentram em instituições educacionais em contexto municipal e estadual, utilizando, em sua maioria, os gastos com educação como inputs e indicadores educacionais institucionais como outputs. Todos os trabalhos identificados utilizaram o modelo DEA (BCC e - ou - CCR), cujos achados expõem baixos níveis de eficiência na gestão dos recursos públicos na educação e baixa frequência de instituições educacionais consideradas eficientes.

Além disso, a fim de garantir a robustez dos resultados, aplicamos o escore padronizado (Z-teste) para excluir os efeitos de outliers. Outrossim, com o propósito de realizar uma análise da eficiência técnica e de escala dos gastos, utilizamos os modelos DEA com retornos variáveis (BCC) e retornos constantes (CCR) de escala com orientação para outputs. Aplicamos a modelagem DEA combinado com o índice de Malmquist, para verificar se houve mudança de eficiência no período analisado. Por fim, deve-se ressaltar a necessidade de avaliar o nível de eficiência dos resultados das instituições de EPCT a fim de aprimorar o planejamento, bem como redefinir políticas educacionais.

\section{METODOLOGIA}

A Rede Federal de EPCT é composta pelos Institutos Federais de Educação, Ciência e Tecnologia (IFs), pela Universidade Tecnológica Federal do Paraná (UTFPR), pelos Centros Federais de Educação Tecnológica Celso Suckow da Fonseca (CEFET-RJ) e de Minas Gerais (CEFET-MG), pelas Escolas Técnicas Vinculadas às Universidades Federais e pelo Colégio Pedro II, totalizando 74 instituições (Lei n. 11892, 2008).

A amostra inicial deste estudo é representada por 38 IFs, no período entre 2008 e 2017, totalizando 380 observações. Desse conjunto, foram excluídas 92 observações por ausência de dados nos relatórios de gestão dos IFs. Considerando que a metodologia DEA é sensível a outliers, optamos por excluir 11 observações consideradas como tal, aplicando o teste de escore padronizado (Z-teste), para valores superiores a 3. Esse procedimento foi sugerido e aplicado por Costa et al. (2012) e Furtado e Campos (2015).

Além disso, existe uma recomendação empírica de que o número de DMUs seja, pelo menos, o dobro ou o triplo de variáveis utilizadas (Gomes, Mangabeira, \& Mello, 2005). Em razão disso, excluímos os períodos de 2008 e 2009, uma vez que apresentaram a relação quantitativa DMUs/variáveis menor do que 3.

Sendo assim, para a DEA, a amostra final deste estudo é composta por 263 observações, distribuídas, de forma desbalanceada, entre 2010 e 2017, que representa 69,2\% da população. A distribuição amostral dos IFs por região e por ano/período está descrita na Tabela 1. 
Tabela 1 - Composição da amostra do estudo

\begin{tabular}{|c|c|c|c|c|c|c|c|c|c|c|}
\hline Região & 2010 & 2011 & 2012 & 2013 & 2014 & 2015 & 2016 & 2017 & Total & (\%) \\
\hline Centro-Oest & 3 & 3 & 3 & 3 & 4 & 4 & 4 & 2 & 26 & 9,89 \\
\hline Nordeste & 8 & 8 & 11 & 11 & 11 & 11 & 11 & 11 & 82 & 31,18 \\
\hline Norte & 5 & 6 & 7 & 7 & 6 & 6 & 5 & 3 & 45 & 17,11 \\
\hline Sudeste & 6 & 7 & 7 & 7 & 9 & 9 & 9 & 8 & 62 & 23,57 \\
\hline Sul & 5 & 5 & 5 & 6 & 7 & 7 & 6 & 7 & 48 & 18,25 \\
\hline Total & 27 & 29 & 33 & 34 & 37 & 37 & 35 & 31 & 263 & 100,00 \\
\hline
\end{tabular}

Fonte: Elaborado pelos autores.

Os dados utilizados na pesquisa para compor os inputs e os outputs foram coletados nos relatórios de gestão dos respectivos IFs no website do Tribunal de Contas da União (TCU) (https://portal.tcu.gov.br/ contas/contas-e-relatorios-de-gestao/), já que essas instituições são passíveis aos processos de prestação de contas da administração pública federal e devem divulgar alguns indicadores - acadêmicos, administrativos, socioeconômicos e de gestão de pessoas - conforme os termos do Acórdão TCU 2.267 (2005).

Os escores de eficiência produtiva foram calculados com o auxílio do DEA, aplicando o modelo de eficiência com retornos variáveis de escala (BCC), orientado para output, conforme Equação 1. A abordagem BCC é adequada para o contexto em análise, uma vez que os IFs têm maior autonomia para afetar os outputs e menor possibilidade de alterar os inputs. A orientação para output fundamenta-se na possibilidade de maximizar os produtos gerados, mantendo os níveis de recursos utilizados, em razão do orçamento limitado, além de considerar que a relação entre insumos e produtos não é necessariamente proporcional (Costa \& Castanhar, 2003, Cavalcante \& Andriola, 2012).

$$
\operatorname{Minh}_{0}=\sum_{i=1}^{r} v_{i} x_{i 0}-u
$$

Sujeitoa:

$$
\sum_{i=1}^{r} v_{i} x_{i k}-\sum_{j=1}^{s} u_{j} y_{j k}-v \leq 0, k=1,2, \ldots n
$$

$$
\begin{gathered}
u_{j}, v_{i} \geq 0 \forall j, i \\
v \in R
\end{gathered}
$$

Adicionalmente, foram calculados os níveis de eficiência com retornos constantes de escala (CCR), orientado a output, conforme Equação 2. Esse procedimento foi realizado a fim de calcular o índice de eficiência de escala (ESC), através da razão entre os resultados modelos de eficiência CCR e BCC, ambos orientados a output.

(2)

$$
\begin{gathered}
\sum_{i=1}^{r} v_{i} x_{i k}-\sum_{j=1}^{s} u_{j} y_{j k} \leq 0, k=1,2, \ldots n \\
u_{j}, v_{i} \geq 0 \forall j, i
\end{gathered}
$$

Em que: $h$. representa a eficiência; $x_{i k}$ e $y_{i k}$ representam os inputs $i$ e outputs $j$ da DMU.; $x_{i 0}$ e $y_{i 0}$ representam os inputs . e outputs . da DMU.. A análise de eficiência técnica apresenta um escore, que oscila entre "0" e "1". Nesse intervalo, a DMU com índice igual a 1 é considerada eficiente quanto à relação produto/ 
insumo, identificando-a como a melhor DMU dentro do conjunto para servir de referência (benchmark) para as demais unidades.

Para efetivação da análise de eficiência, a próxima etapa consiste em definir as variáveis de insumo (inputs) e de produtos (outputs). O Quadro 2 apresenta o detalhamento das variáveis do estudo, em que são utilizadas medidas (não) financeiras, para os inputs, e medidas de desempenho institucional, para os outputs.

Quadro 2 - Inputs e outputs utilizados nos modelos DEA

\begin{tabular}{|c|c|c|c|}
\hline \multicolumn{4}{|l|}{ Inputs } \\
\hline Variável & Operacionalização & Interpretação & Fundamentação \\
\hline $\mathrm{GCA}$ & Importar imagen & $\begin{array}{l}\text { Indica o custo anual de } \\
\text { um aluno matriculado na } \\
\text { instituição. }\end{array}$ & $\begin{array}{l}\text { Furtado e Campos } \\
\text { (2015), Amorim et } \\
\text { al. (2017), Castro e } \\
\text { Sousa (2018) }\end{array}$ \\
\hline $\mathrm{RAD}$ & Importar imagen & $\begin{array}{l}\text { Indica o quantitativo de } \\
\text { alunos por número de } \\
\text { docentes. }\end{array}$ & $\begin{array}{l}\text { Kaveski et al. } \\
\text { (2015), Furtado e } \\
\text { Campos (2015), } \\
\text { Gresele Krukoski } \\
\text { (2018) }\end{array}$ \\
\hline $\mathrm{TCD}$ & Importar imagen & $\begin{array}{l}\text { Indica a qualidade } \\
\text { técnica e profissional do } \\
\text { corpo docente. }\end{array}$ & $\begin{array}{l}\text { Costa et al. (2012), } \\
\text { Furtado e Campos } \\
\text { (2015) }\end{array}$ \\
\hline utput & & & \\
\hline
\end{tabular}

Fonte: Elaborado pelos autores.

Legenda GCA - Gastos correntes por aluno; RAD - Relação alunos/docentes; TCD - Índice de titulação do corpo docente; RCM - Relação concluintes por aluno matriculado. A titulação do corpo docente está classificada em cinco categorias: graduação

(G), aperfeiçoamento (A), especialização (E), mestrado (M) e doutorado (D). Dados conforme Acordão TCU 2.267 (2005).

Para analisar a evolução da eficiência e da produtividade dos IFs entre 2010 e 2017, utilizamos a análise DEA painel (Färe, Grosskopf, Norris, \& Zhang, 1994) através do índice de produtividade de Malmquist (IPM), conforme equação abaixo (Equação 3). O referido índice evidencia o desempenho da produtividade dos fatores de produção, permitindo, inclusive, a decomposição nos componentes de variação tecnológica (TECHCH), variação da eficiência produtiva $(\mathrm{EFFCH})$, variação da eficiência técnica pura $(\mathrm{PECH}) \mathrm{e}$ variação da eficiência de escala (SECH).

$$
M_{0}\left(x_{t+1}, y_{t+1}, x_{t}, y_{t}\right)=\left(\frac{\frac{d_{0}^{t}\left(x_{t+1}, y_{t+1}\right)}{d_{0}^{t}\left(x_{t}, y_{t}\right)} * d_{0}^{t+1}\left(x_{t+1}, y_{t+1}\right)}{d_{0}^{t+1}\left(x_{t}, y_{t}\right)}\right)^{\frac{1}{2}}
$$

(3)

O índice pode assumir três resultados distintos: (1) quando o IPM $>1$ indica que há melhoria de produtividade; (2) quando o IPM = 0 indica que não há mudança no nível de produtividade; e (3) quando o IPM $<1$ indica que há perda de produtividade. As estimações foram realizadas através do software Data Envelopment Analysis (Computer) Program - DEAP (versão 2.1).

Por fim, procedemos à análise descritiva e de variância (Anova), aplicando os testes de Shapiro-Wilk e Shapiro-Francia para verificar a normalidade dos dados, e o teste de Bartlett para verificar a hipótese de igualdade de variâncias. As referidas análises foram realizadas no Stata (versão 13.0). 


\section{ANÁLISE E DISCUSSÃO DOS RESULTADOS}

A fim de proporcionar um panorama dos dados da pesquisa, apresentamos a análise descritiva das variáveis de input e de output, bem como os resultados dos níveis de eficiência - técnica (BCC e CCR) e de escala (ESC), que equaciona os modelos de eficiência técnica - conforme Tabela 2.

Tabela 2 - Análise descritiva

\begin{tabular}{llllllllll}
\hline Variáveis & Obs. Média & DP & CV & Mín. & p25 & p50 & p75 & Máx. \\
\hline GCA & 263 & $11.634,67$ & $4.054,80$ & 34,85 & $1.684,41$ & $8.460,50$ & $11.311,16$ & $14.901,10$ & $26.614,82$ \\
\hline RAD & 263 & 23,01 & 7,40 & 32,18 & 4,81 & 18,46 & 21,82 & 26,50 & 68,21 \\
\hline TCD & 263 & 3,63 & 0,46 & 12,69 & 1,85 & 3,33 & 3,68 & 3,92 & 4,80 \\
RCM & 263 & 44,19 & 15,41 & 34,87 & 0,00 & 34,60 & 45,40 & 53,82 & 68,21 \\
\hline BCC & 263 & 0,74 & 0,24 & 0,33 & 0,04 & 0,57 & 0,76 & 1,00 & 1,00 \\
\hline CCR & 263 & 0,66 & 0,25 & 0,36 & 0,00 & 0,50 & 0,68 & 0,84 & 1,00 \\
\hline ESC & 263 & 0,91 & 0,15 & 0,16 & 0,00 & 0,91 & 0,96 & 0,99 & 1,00 \\
\hline
\end{tabular}

Fonte: Elaborado pelos autores.

Legenda GCA - Gastos correntes por aluno; RAD - Relação alunos/docentes; TCD - Índice de titulação do corpo docente; RCM - Relação concluintes por aluno matriculado; CCR - Eficiência por retornos constantes de escala; BCC - Eficiência por retornos variáveis de escala; ESC - Eficiência de escala.

O resultado sugere a existência de elevada dispersão quanto à RAD. Em relação a esta, o IFAC (Acre), em 2010, apresentou uma relação de, aproximadamente, 5 (cinco) alunos por docente, enquanto que, em 2013, o IFSULDEMINAS (Sul de Minas Gerais) divulgou que havia cerca de 68 alunos por docente. Quanto às medidas de eficiência técnica (BCC e CCR), as dispersões são semelhantes àquelas encontradas nas variáveis de input e output.

Convém destacar, portanto, que a eficiência técnica média no período analisado foi de $73,7 \%$, para o modelo BCC, e de 66,3\%, para o modelo CCR. Essas evidências convergem com parte dos estudos empíricos apresentados no Quadro 1 (Lourenço et al., 2017, Amorim et al., 2017). Outros trabalhos, por sua vez, encontraram escores de eficiência média menores, de 47,0\% em escolas de ensino municipal (Castro \& Sousa, 2018) e de 55,3\% em instituições de ensino superior (Costa et al., 2012). Noutro turno, analisando uma amostra de apenas 12 escolas militares do Estado da Paraíba no período de 2014, Silva et al. (2016) encontraram escores de eficiência média de $96,7 \%$.

Esses resultados sugerem que as especificidades de cada instituição educacional - municipal, estadual, tecnológicas e militares - podem ser afetadas no nível de eficiência dos gastos públicos em educação. A divergência nos níveis de eficiência pode indicar a necessidade de um estudo identificando os fatores que possam determinar - majorando ou reduzindo - o nível de eficiência. Apresentamos, a seguir, o ranking dos IFs, utilizando como parâmetro a média de eficiência, com base no modelo de retornos variáveis escala (BCC), durante os períodos de dados disponibilizados pelas respectivas instituiçóes de educação. $\mathrm{O}$ ranking está disposto na Tabela 3. 
Tabela 3 - Ranking de eficiência dos IFs

\begin{tabular}{|c|c|c|c|c|c|c|c|c|c|c|}
\hline Ranking & IFs & Região & $\begin{array}{l}\text { No. de } \\
\text { períodos }\end{array}$ & GCA & RAD & TCD & $\mathrm{RCM}$ & $\mathrm{BCC}$ & CCR & ESC \\
\hline $1^{\circ}$ & IFG & $\mathrm{CO}$ & 3 & $16.815,15$ & 14,143 & 4,013 & 0,416 & 1,000 & 0,827 & 0,827 \\
\hline $2^{\circ}$ & IFSULDEMINAS & $\mathrm{SE}$ & 5 & $7.752,18$ & 41,370 & 4,078 & 0,671 & 1,000 & 0,986 & 0,986 \\
\hline $3^{\circ}$ & IFAP & $\mathrm{N}$ & 6 & $6.460,39$ & 27,583 & 3,177 & 0,646 & 0,980 & 0,969 & 0,989 \\
\hline $4^{\circ}$ & IFSP & SE & 4 & $11.917,08$ & 17,400 & 3,838 & 0,495 & 0,959 & 0,877 & 0,916 \\
\hline $5^{\circ}$ & IF Baiano & NE & 6 & $14.834,25$ & 19,093 & 3,917 & 0,487 & 0,904 & 0,792 & 0,885 \\
\hline $6^{\circ}$ & IFPA & $\mathrm{N}$ & 6 & $9.134,68$ & 27,310 & 3,463 & 0,534 & 0,893 & 0,841 & 0,943 \\
\hline $7^{\circ}$ & IFPR & $\mathrm{S}$ & 5 & $7.337,22$ & 38,178 & 3,762 & 0,518 & 0,892 & 0,799 & 0,906 \\
\hline $8^{\circ}$ & IFMA & NE & 8 & $10.774,97$ & 22,615 & 3,200 & 0,617 & 0,882 & 0,861 & 0,972 \\
\hline $9^{\circ}$ & IFRN & NE & 8 & $11.044,74$ & 24,876 & 3,521 & 0,592 & 0,875 & 0,838 & 0,956 \\
\hline $10^{\circ}$ & IF Sudeste & SE & 7 & $12.387,03$ & 21,643 & 3,463 & 0,563 & 0,864 & 0,814 & 0,938 \\
\hline $11^{\circ}$ & IFAL & NE & 6 & $11.524,28$ & 19,775 & 3,635 & 0,387 & 0,847 & 0,630 & 0,777 \\
\hline $12^{\circ}$ & IFTO & $N$ & 7 & $10.471,41$ & 22,024 & 2,771 & 0,340 & 0,843 & 0,529 & 0,681 \\
\hline $13^{\circ}$ & IFAC & $\mathrm{N}$ & 6 & $12.721,47$ & 14,412 & 3,297 & 0,271 & 0,820 & 0,463 & 0,633 \\
\hline $14^{\circ}$ & IFC & $\mathrm{S}$ & 8 & $16.041,86$ & 15,953 & 3,936 & 0,444 & 0,816 & 0,758 & 0,918 \\
\hline $15^{\circ}$ & IFNMG & SE & 7 & $11.620,90$ & 19,701 & 3,570 & 0,504 & 0,815 & 0,774 & 0,946 \\
\hline $16^{\circ}$ & IFPI & NE & 7 & $9.520,94$ & 25,439 & 3,286 & 0,446 & 0,793 & 0,711 & 0,909 \\
\hline $17^{\circ}$ & IFES & $\mathrm{SE}$ & 7 & $14.141,09$ & 21,357 & 3,850 & 0,527 & 0,782 & 0,752 & 0,962 \\
\hline $18^{\circ}$ & IFSC & $\mathrm{s}$ & 8 & $10.091,61$ & 25,483 & 3,779 & 0,450 & 0,782 & 0,675 & 0,875 \\
\hline $19^{\circ}$ & IF Goiano & $\mathrm{CO}$ & 8 & $12.901,47$ & 20,588 & 3,989 & 0,521 & 0,781 & 0,751 & 0,954 \\
\hline $20^{\circ}$ & IFRR & $N$ & 7 & $14.201,10$ & 22,606 & 3,241 & 0,438 & 0,773 & 0,671 & 0,868 \\
\hline $21^{\circ}$ & IFRS & $S$ & 8 & $12.009,41$ & 22,186 & 4,033 & 0,525 & 0,768 & 0,730 & 0,951 \\
\hline $22^{\circ}$ & IF SERT $\tilde{\mathrm{A} O}$-PE & NE & 8 & $10.546,98$ & 23,509 & 3,300 & 0,416 & 0,741 & 0,641 & 0,879 \\
\hline $23^{\circ}$ & IFMG & SE & 8 & $13.537,77$ & 21,094 & 3,740 & 0,461 & 0,698 & 0,662 & 0,941 \\
\hline $24^{\circ}$ & IFFluminense & $\mathrm{SE}$ & 8 & $10.210,81$ & 22,978 & 3,321 & 0,430 & 0,695 & 0,669 & 0,955 \\
\hline $25^{\circ}$ & IFFar & $\mathrm{S}$ & 8 & $13.896,24$ & 21,284 & 4,023 & 0,467 & 0,691 & 0,653 & 0,940 \\
\hline $26^{\circ}$ & IFAM & $\mathrm{N}$ & 7 & $8.435,91$ & 29,739 & 3,256 & 0,440 & 0,688 & 0,605 & 0,901 \\
\hline $27^{\circ}$ & IFTM & $\mathrm{SE}$ & 8 & $13.720,89$ & 21,181 & 3,758 & 0,360 & 0,656 & 0,552 & 0,871 \\
\hline $28^{\circ}$ & IFS & NE & 8 & $11.511,04$ & 22,534 & 3,569 & 0,351 & 0,655 & 0,531 & 0,855 \\
\hline $29^{\circ}$ & IFSul & $\mathrm{S}$ & 7 & $13.627,60$ & 21,546 & 3,670 & 0,406 & 0,626 & 0,596 & 0,950 \\
\hline $30^{\circ}$ & IFBA & NE & 7 & $10.727,59$ & 23,347 & 3,523 & 0,403 & 0,622 & 0,601 & 0,965 \\
\hline $31^{\circ}$ & IFRJ & SE & 8 & $14.577,36$ & 16,941 & 3,925 & 0,352 & 0,616 & 0,564 & 0,912 \\
\hline $32^{\circ}$ & IFPE & NE & 8 & $9.280,80$ & 27,559 & 3,630 & 0,408 & 0,616 & 0,558 & 0,922 \\
\hline $33^{\circ}$ & IFMT & $\mathrm{CO}$ & 7 & $11.870,30$ & 24,570 & 4,647 & 0,408 & 0,576 & 0,528 & 0,907 \\
\hline $34^{\circ}$ & IFCE & NE & 8 & $10.182,99$ & 23,699 & 3,524 & 0,368 & 0,565 & 0,546 & 0,954 \\
\hline $35^{\circ}$ & IFB & $\mathrm{CO}$ & 8 & $10.056,39$ & 24,776 & 3,649 & 0,320 & 0,540 & 0,471 & 0,912 \\
\hline $36^{\circ}$ & IFMS & $\mathrm{S}$ & 4 & $14.810,74$ & 19,515 & 3,740 & 0,282 & 0,483 & 0,466 & 0,960 \\
\hline $37^{\circ}$ & IFPB & NE & 8 & $11.991,32$ & 22,658 & 3,796 & 0,328 & 0,473 & 0,452 & 0,953 \\
\hline $38^{\circ}$ & IFRO & $N$ & 6 & $10.170,45$ & 25,187 & 3,108 & 0,230 & 0,401 & 0,343 & 0,892 \\
\hline \multicolumn{4}{|c|}{ Média total } & $11.634,67$ & 23,008 & 3,626 & 0,442 & 0,737 & 0,663 & 0,909 \\
\hline
\end{tabular}

Fonte: Elaborado pelos autores.

Nota A classificação dos IFs não levou em consideração o quantitativo de períodos em que o nível de eficiência foi calculado. Regiões: Norte (N), Nordeste (NE), Centro-Oeste (CO), Sudeste (SE) e Sul (S). Legenda: GCA - Gastos correntes por aluno; RAD - Relação alunos/docentes; TCD - Índice de titulação do corpo docente; RCM - Relação concluintes por aluno matriculado; CCR - Eficiência por retornos constantes de escala; BCC - Eficiência por retornos variáveis de escala; ESC - Eficiência de escala.

Posteriormente, aplicamos a análise de variância (Anova) para verificar a existência de diferença nas médias das variáveis de input e output, bem como dos escores de eficiência técnica (BCC/CCR) e de escala (ESC) ao longo do período analisado e entre as regiões. Os resultados estão descritos na Tabela 4. 
Tabela 4 - Análise de variância

\begin{tabular}{|c|c|c|c|c|c|c|c|c|c|c|c|c|c|c|c|}
\hline \multicolumn{16}{|c|}{ Painel A - Análise de variância por período } \\
\hline Ano & Obs. & GCA & & RAD & & TCD & & $\mathrm{RCM}$ & & $\mathrm{BCC}$ & & CCR & & ESC & \\
\hline 2010 & 27 & $9.543,8$ & & 17,98 & & 3,34 & & 0,34 & & 0,62 & & 0,51 & & 0,85 & \\
\hline 2011 & 29 & $9.783,2$ & & 19,53 & & 3,30 & & 0,37 & & 0,64 & & 0,51 & & 0,85 & \\
\hline 2012 & 33 & $7.422,6$ & & 26,36 & & 3,45 & & 0,46 & & 0,67 & & 0,59 & & 0,88 & \\
\hline 2013 & 34 & $9.446,1$ & & 28,75 & & 3,58 & & 0,49 & & 0,74 & & 0,68 & & 0,93 & \\
\hline 2014 & 37 & 12.573 & 59 & 22,12 & & 3,60 & & 0,49 & & 0,78 & & 0,74 & & 0,95 & \\
\hline 2015 & 37 & 13.231 & 16 & 22,69 & & 3,78 & & 0,45 & & 0,77 & & 0,65 & & 0,87 & \\
\hline 2016 & 35 & 14.268 & 24 & 23,57 & & 3,92 & & 0,46 & & 0,80 & & 0,76 & & 0,96 & \\
\hline 2017 & 31 & 16.072 & 17 & 21,59 & & 3,92 & & 0,44 & & 0,84 & & 0,81 & & 0,97 & \\
\hline Estatística & & 30,01 & $* * *$ & 8,17 & $* * *$ & 11,38 & $* * *$ & 4,12 & $* * *$ & 3,71 & $* * *$ & 8,58 & $* * *$ & 4,17 & $* * *$ \\
\hline Teste Bartl & & 8,07 & & 42,95 & $* * *$ & 28,39 & $* * *$ & 41,98 & $* * *$ & 23,56 & $* * *$ & 27,37 & $* * *$ & 137,52 & $* * *$ \\
\hline \multicolumn{16}{|c|}{ Painel B - Análise de variância por região } \\
\hline Região & Obs. & GCA & & RAD & & TCD & & RCM & & $\mathrm{BCC}$ & & CCR & & ESC & \\
\hline $\begin{array}{l}\text { Centro- } \\
\text { beste }\end{array}$ & 26 & 12.200 &, 02 & 22,21 & & 4,06 & & 0,42 & & 0,68 & & 0,61 & & 0,91 & \\
\hline Nordeste & 82 & 11.006 & 75 & 23,35 & & 3,53 & & 0,44 & & 0,72 & & 0,65 & & 0,91 & \\
\hline Norte & 45 & 10.281 & 80 & 24,17 & & 3,18 & & 0,41 & & 0,77 & & 0,63 & & 0,84 & \\
\hline Sudeste & 62 & 12.416 & 89 & 22,14 & & 3,71 & & 0,47 & & 0,76 & & 0,72 & & 0,93 & \\
\hline Sul & 48 & 12.659 &, 07 & 22,90 & & 3,87 & & 0,45 & & 0,73 & & 0,68 & & 0,93 & \\
\hline Estatística & & 3,33 & $* * *$ & 0,61 & & 30,75 & $* * *$ & 1,25 & & 0,97 & & 1,43 & & 3,22 & $* * *$ \\
\hline Teste Bartl & & 6,04 & & 16,80 & $* * *$ & 15,20 & $* * *$ & 25,14 & $* * *$ & 14,29 & $* * *$ & 16,64 & $* * *$ & 83,19 & $* * *$ \\
\hline
\end{tabular}

Fonte: Elaborado pelos autores.

Nota As variáveis apresentam distribuição normal, ao nível de 5\%, identificados a partir do teste de Shapiro-Wilk e Shapiro-Francia. Por essa razão, optamos por utilizar o teste de Bartlett para verificar a hipótese de igualdade de variâncias.

Legenda: GCA - Gastos correntes por aluno; RAD - Relação alunos/docentes; TCD - Índice de titulação do corpo

docente; RCM - Relação concluintes por aluno matriculado; CCR - Eficiência por retornos constantes de escala;

BCC - Eficiência por retornos variáveis de escala; ESC - Eficiência de escala. ${ }^{* * *}$ representa nível de significância de $1 \%$.

Nota-se que a eficiência com retornos variáveis de escala (BCC) nos IFs tem aumentado ano a ano, mostrando uma taxa de crescimento de $35,5 \%$ entre 2010 e 2017 . Os resultados podem ser considerados expressivos, considerando a magnitude do processo de expansão, uma vez que foram criados 530 campi entre 2010 e 2016, com crescimento de 26,2\% (Portaria MEC n. 378, 2016). A taxa de crescimento de eficiência do modelo CCR foi de 58,8\%, quando se presume que a geração de inputs e outputs é proporcional.

As variáveis de gastos correntes por aluno (GCA) e a titulação do corpo docente (TCD) apresentam crescimento aparente no período analisado. $\mathrm{O}$ aumento concomitante dessas variáveis ocorre em razão da existência do plano de carreiras e cargos (Lei n. 12772, 2012), uma vez que a remuneração está atrelada à titulação docente. As variáveis RAD (input) e RCM (output) apresentam crescimento até 2014, contudo, decrescem a partir dessa data. Esse resultado pode estar relacionado à eclosão da greve de professores e servidores dos institutos e universidades federais, iniciada no primeiro semestre de 2014 (Sarraes, 2014). Nesse sentido, a literatura encontrou evidências que as greves na educação podem aumentar a evasão escolar (Fonseca et al., 2018, Santos et al., 2019), reduzindo o quantitativo de alunos nas instituições de ensino.

Por outro lado, os resultados mostram que as regiões Norte e Sul apresentaram, respectivamente, o menor e o maior valor médio dispendido por aluno (GCA). Embora a região Norte apresente, aparentemente, maior nível de eficiência, as regiões Sul e Sudeste apresentaram os maiores níveis de eficiência de escala, indicando que os IFs dessas respectivas regiões estão operando em escala próxima ao nível ótimo.

Nesse contexto, Lourenço et al. (2017) encontraram que a maioria das instituições municipais de ensino com maior eficiência estão localizadas na região Norte e Nordeste. Kaveski et al. (2015), por outro lado, ao analisar a eficiência das unidades estaduais brasileiras, identificaram que as regióes Sudeste e Sul apresentaram os maiores escores de eficiência técnica. Costa et al. (2012) encontraram que as instituições de ensino superior na região Sudeste e Norte são mais eficientes e com maiores números de benchmarks. Essas divergências 
podem estar associadas à competência da gestão dos recursos públicos na educação - municipal e estadual -, que é específica.

O índice de Malmquist avalia a produtividade - relação produto/insumo - em diferentes intervalos de tempo (bianual), decompondo-os em índices que refletem a eficiência técnica e a mudança tecnológica. A Tabela 5 contém os resultados da referida análise.

Tabela 5 - Evolução da eficiência e da produtividade

\begin{tabular}{lllllll}
\hline Período & Obs. & EFFCH & TECHCH & PECH & SECH & IPM \\
\hline $2010-2011$ & 24 & 1,131 & 1,082 & 1,531 & 0,901 & 1,240 \\
\hline $2011-2012$ & 26 & 1,780 & 1,034 & 1,724 & 1,071 & 1,837 \\
\hline $2012-2013$ & 32 & 1,211 & 0,812 & 1,147 & 1,056 & 0,983 \\
\hline $2013-2014$ & 33 & 1,084 & 0,955 & 1,042 & 1,040 & 1,035 \\
\hline $2014-2015$ & 32 & 0,918 & 0,945 & 0,940 & 0,977 & 0,868 \\
\hline $2015-2016$ & 35 & 1,176 & 0,830 & 1,067 & 1,102 & 0,977 \\
\hline $2016-2017$ & 29 & 1,088 & 0,934 & 1,079 & 1,008 & 1,016 \\
\hline Média & - & $\mathbf{1 . 1 9 8}$ & $\mathbf{0 . 9 4 2}$ & $\mathbf{1 . 2 1 9}$ & $\mathbf{1 . 0 2 2}$ & $\mathbf{1 . 1 3 7}$
\end{tabular}

Fonte: Elaborado pelos autores.

De modo geral, os resultados indicam que, no período analisado, houve avanço nos níveis de produtividade (IPM) nos IFs, apresentando um crescimento de $13,7 \%$ na relação produto/insumo. Esse resultado decorre, principalmente, da evolução dos índices de eficiência produtiva (19,8\%) e de eficiência técnica pura (21,9\%), cujo efeito foi amenizado pela involução do índice de variação tecnológica $(-5,8 \%)$. O resultado negativo da variação tecnológica implica em um regresso ocupado pelos IFs, que almejam acelerar seu processo técnico em convergência às instituições "líderes" no contexto educacional, que apresentam matrizes produtivas com maior densidade tecnológica. Esse processo, denominado catching-up, representa a necessidade de as instituições realizarem esforços para reduzir a distância em relação à fronteira tecnológica, o que parece não ocorrer.

Parte desse avanço deve-se à metade dos IFs, que apresentaram índices de produtividade de Malmquist (IPM) superior a uma unidade. Destes, o IFRJ (Rio de Janeiro) apresentou o maior crescimento nos níveis de produtividade, de 21,0\%, explicado pelo progresso nos níveis de eficiência (produtiva, técnica pura e de escala), contudo, com um regresso nos níveis de variação tecnológica. Por outro lado, o IFF (Fluminense) apresentou o maior decréscimo do índice de produtividade, de -13,4\%. Apesar disso, a região sudeste ainda acumulou o maior avanço nos níveis de produtividade, com um crescimento de 5,1\%. Deve-se ressaltar ainda que a maior evolução de produtividade ocorreu nos períodos iniciais do processo de expansão da Rede Federal de EPCT, em que se observou uma variação na produtividade de 24,0\%, entre 2010 e 2011, e de 83,7\%, entre 2011 e 2012. Por outro lado, a maior involução na produtividade foi de 13,2\% (2014-2015), em razão, talvez, das greves ocorridas nos institutos e nas universidades federais no ano de 2014 (Sarraes, 2014).

Esses resultados sugerem que, ao longo do processo de expansão da Rede Federal de EPCT, os IFs obtiveram ganhos de produtividade, apesar do regresso tecnológico evidenciado. Esse achado diverge da hipótese aqui proposta, de que os níveis de produtividade e de eficiência dos IFs do Brasil decresceram ao longo do processo de expansão da Rede Federal de EPCT. Desse modo, as evidências apontam que, apesar da expansão da referida rede, o ganho de produtividade é percebido, embora ainda seja pouco representativo.

Assim, o processo de expansão da educação no contexto dos IFs não gerou perda de expectativa relacionada aos resultados esperados, alunos formados em diferentes modalidades e níveis de ensino. Por fim, embora a literatura sugira que a expansão do ensino possa implicar na redução da proficiência dos alunos, na necessidade de formação docente, na capacitação da gestão escolar e na garantia de manutenção da infraestrutura (Cavalcante \& Andriola, 2012; Furtado \& Campos, 2015; Krawczyk, 2013), os resultados 
fazem notar que a combinação dos inputs na geração dos outputs gerou um avanço na produtividade nos IFs do Brasil.

\section{CONSIDERAÇÕES FINAIS}

Este estudo teve o objetivo de analisar a evolução da produtividade e da eficiência dos gastos públicos em educação nas instituições federais de EPCT no período entre 2010 e 2017. Para tanto, os dados foram coletados nos Relatórios de Gestão, publicados no portal do Tribunal de Contas da União (TCU). Foram empregadas a Análise Envoltória de Dados (DEA) e o índice de Malmquist (IPM) para identificar o nível de eficiência e sua respectiva evolução ao longo do período analisado.

A análise descritiva evidenciou diferenças no desembolso financeiro (GCA) entre as unidades tomadoras de decisão (DMUs). Esse resultado deve-se, dentre outras razões, à variedade de cursos ofertados por essas instituições que podem demandar infraestrutura e custeio de ambientes para prática laboratorial, agropecuária, industrial, dentre outros. Outro achado relevante para a pesquisa é que a rede federal de ensino apresentou valor médio de alunos por professor (23 alunos por professor) próximo ao projetado pelo Plano Nacional de Educação (PNE), que é de 20 alunos-equivalentes para cada docente entre os cursos técnicos e de qualificação profissional (Lei n. 13005, 2014).

De modo geral, comparativamente entre os períodos estudados, detectam-se diferenças positivas nas variáveis de input, output e nos resultados de eficiência, indicando crescimento, porém em escalas diferentes. Quando a comparação é realizada por regiões, as diferenças são percebidas apenas nos inputs. Em ambas as constatações, é reforçado o indício de que maiores gastos e profissionais com elevada capacitação não garantem maiores retornos para os IFs.

Posteriormente, ao analisar o nível de eficiência entre 2010 e 2017, foi identificado um crescimento médio de 13,7\%, embora esse resultado tenha sido retraído em razão de um decrescimento da variação tecnológica. Esses resultados conduzem à refutação da hipótese do estudo, ou seja, os níveis de produtividade e de eficiência dos IFs cresceram ao longo do processo de expansão da rede federal de EPCT. Ao contrário do que foi proposto, os resultados sugerem que os níveis de produtividade e de eficiência dos IFs do Brasil cresceram ao longo do processo de expansão da rede federal EPCT.

Este estudo diverge dos demais por utilizar a metodologia de DEA painel, aplicando o índice de Malmquist para identificar a variação dos índices de produtividade no setor educacional, calculado ano a ano, permitindo identificar as rupturas de eficiência ao longo do processo de expansão da rede federal de EPCT. Este trabalho, além de descrever os níveis de eficiência, classifica as instituições de EPCT em um ranking, conforme o modelo de retornos variáveis de escala (BCC).

Apesar de a literatura defender que os processos de expansão do ensino gerarem a perda de expectativa relacionada à qualidade do ensino (Marchelli, 2010, Cavalcante \& Andriola, 2012, Krawczyk, 2013, Furtado \& Campos, 2015), os resultados deste estudo confrontam essa literatura. Em teoria, cabe outros estudos identificarem os fatores que possam explicar a evolução da eficiência e da produtividade nessas instituições, considerando as especificidades dessas instituições: amplitude das modalidades de ensino dos cursos ofertados (médio, técnico, superior e pós-graduação), processo seletivo de candidatos, interiorização das instituições (multicampi) e pilares atendidos (ensino, pesquisa e extensão).

\section{REFERÊNCIAS}

Agasisti, T. (2014). The Efficiency of Public Spending on Education: an empirical comparison of EU countries. European Journal of Education, 49 (4), 543-557.

Amorim, K. A. F., Diniz, J. A., de Lima, S. C. (2017). A visão do controle externo na eficiência dos gastos públicos com educação fundamental. Revista de Contabilidade e Organizações, 11(29), 56-67. 
Banker, R. D., Charnes, A., Cooper, W. W. (1984). Some models for estimating technical scale inefficiencies in data envelopment analysis. Management Science, 30(9), 1078-1092.

Begnini, S., Tosta, H. T. (2017). A eficiência dos gastos públicos com a educação fundamental no Brasil: uma aplicação da análise envoltória de dados (DEA). Revista Economia Gestão, 17(46), 43-59.

Castro, M. S., Sousa, E. P. de (2018). Eficiência dos gastos públicos da rede de ensino municipal cearense. Gestão Regionalidade, 34(100), 82-109.

Cavalcante, S. M., Andriola, W. B. (2012). Avaliação da eficiência dos cursos de Graduação da Universidade Federal do Ceará (UFC) através da Análise Envoltória de dados (DEA). Revista Iberoamericana de Evaluación Educativa, 5(3), 291-314.

Charnes, A., Cooper, W. W., Rhodes, E. (1978). Measuring the efficiency of decision-making units. European Journal of Operational Research, 2, 429-444.

Costa, F. L., Castanhar, J. C. (2003). Avaliação de programas públicos: desafios conceituais e metodológicos. Revista de Administração Pública, 37(5), 969-992.

Costa, C. C. M., Ferreira, M. A. M., Braga, M. J., Abrantes, L. A. (2015). Fatores associados à eficiência na alocação de recursos públicos à luz do modelo de regressão quantílica. Revista de Administração Pública, 49(5), 1319-1347.

Costa, E. M., Sousa, F. R. de, Souza, H. R. de, Silva, J. L. M. da (2012). Eficiência e desempenho no ensino superior: uma análise da fronteira de produção educacional das IFES brasileiras. Revista de Economia Contemporânea., 16(3), 415-440.

Cuéllar, A. F. S. The Efficiency of Education Expenditure in Latin America and Lessons for Colombia. Desarrollo y Sociedad, 74, 19-67

Diel, E. H., Diel, F. J., Schulz, S. J., Chiarello, T. C., da Rosa, F. S. (2014). Desempenho de municípios brasileiros em relação à estratégia de investimento público em educação. Desenvolvimento em Questão, 12(26), 79-107.

Färe, R., Grosskopf, S., Norris, M., Zhang, Z. (1994). Productivity Growth, Technical Progress, and Efficiency Change in Industrialized Countries. American Economic Review, 84(1), 66.83.

Flach, L., Mattos, L. K., Will, A. R., Roschel, L. F. (2017). Eficiencia de gastos en educación y aprendizaje por los estados de Brasil: un estudio con análisis envolvente de datos. Contabilidad y Negocios: Revista del Departamento Académico de Ciencias Administrativas, 12(23), 111-128.

Firmino, R. G., Filho, P. A. M. (2018). Eficiência na aplicação dos recursos públicos da educação básica. Revista de Contabilidade do Mestrado em Ciências Contábeis da UERJ, 23(1), 28-49.

Fonseca, K. L., Souza, R. F., Costa, G. V. (2018). Impacto da greve dos professores da evasão dos alunos do curso de Administração na UFAM. Revista CESUMAR, 23(1), 99-111.

Furtado, L. L., Campos, G. M. (2016). Grau de eficiência técnica dos Institutos Federais de Educação, Ciência e Tecnologia e a relação dos custos, indicativos de expansão e retenção nos escores de eficiência. Revista de Educação e Pesquisa em Contabilidade, 9(3), 295-312.

Gomes, E. G., Mangabeira, J. A. C., Mello, J. C. C. B. (2005). Análise de envoltória de dados para avaliação de eficiência e caracterização de tipologias em agricultura: um estudo de caso. Revista de Economia e Sociologia Rural, 43(4), 607-631.

Gramani, M. C. (2017). Análise dos determinantes de eficiência educacional do estado do Ceará. Ensaio: Avaliação e Políticas Públicas em Educação, 25(95), 507-526.

Gresele, W. D., Krukoski, F. A. (2018). Eficiência dos gastos municipais em educação no Paraná. Revista Pensamento Contemporâneo em Administração, 12(4), 56-74.

Gusmão, J. B. (2013). Significados da noção de qualidade da educação na arena educacional brasileira. Revista Brasileira de Estudos Pedagógicos, 94(236).

Gupta, S., Verhoeven, M. (2001). A eficiência dos gastos do governo: experiências da África. Journal of Policy Modeling, 23(4), 433-467.

Hanushek, E. A., Luque, J. A. (2003). Efficiency and equity in schools around the world. Economics of education Review, 22(5), 481-502. 
Kaveski, I. D. S., Martins, J. A. S., Scarpin, J. E. (2015). A eficiência dos gastos públicos com o ensino médio regular nas instituições estaduais brasileiras. Enfoque: Reflexão Contábil, 34(1), 29-43.

Krawczyk, N. (2013). Reflexão sobre alguns desafios do ensino médio no Brasil hoje. Cadernos de pesquisa, 41(144), 752-769.

Lei n. 11.892, de 29 de dezembro de 2008 (2008). Institui a Rede Federal de Educação Profissional, Científica e Tecnológica, cria os Institutos Federais de Educação, Ciência e Tecnologia, e dá outras providências. Portal Oficial da Presidência da República, Planalto. Poder executivo, Brasília, DF.

Lei n. 12.772, de 28 de dezembro de 2012 (2012). Dispõe sobre a estruturação do Plano de Carreiras e Cargos de Magistério Federal. Portal Oficial da Presidência da República, Planalto. Poder executivo, Brasília, DF.

Lei n. 13.005, de 25 de junho de 2014 (2014). Aprova o Plano Nacional de Educação - PNE e dá outras providências. Portal Oficial da Presidência da República, Planalto. Poder executivo, Brasília, DF.

Lourenço, R. L., Angotti, M., do Nascimento, J. C. H. B., Sauerbronn, F. F. (2017). Eficiência do gasto público com ensino fundamental: uma análise dos 250 maiores municípios brasileiros. Contabilidade Vista \& Revista, 28(1), 89-116.

Magalhães, E. A., Silveira, S. D. F. R., Abrantes, L. A., Ferreira, M. A. M., Wakim, V. R. (2010). Custo do ensino de graduação em instituições federais de ensino superior: o caso da Universidade Federal de Viçosa. Revista de Administração Pública, 44(3), 637-666.

Magro, C. B. D., Silva, T. P. D. (2016). Desempenho dos gastos públicos em educação e a Lei de Responsabilidade Fiscal das capitais brasileiras. Contabilidade, Gestão e Governança, 19(3), 504-528.

Marchelli, P. S. (2010). Expansão e qualidade da educação básica no Brasil. Cadernos de Pesquisa, 40(140), 561-585.

Monte, M. M., Leopoldino, C. B. (2017). Eficiência dos gastos municipais em educação no Ceará. Revista Pensamento Contemporâneo em Administração, 11(4), 44-55.

Moreira, N. P., Cunha, N. R. S., Ferreira, M. A. M., Silveira, S. D. F. R. (2011). Fatores determinantes da eficiência dos programas de pós-graduação acadêmicos em administração, contabilidade e turismo. Avaliação: Revista da Avaliação da Educação Superior, 16(1), 201-230.

Nascimento, J. C.H. B., Nossa, V., Bernardes, J. R., Sousa, W. D. (2015). A Eficiência dos Maiores Clubes de Futebol Brasileiros: Evidências de uma Análise Longitudinal no Período de 2006 a 2011. Contabilidade Vista Revista, 26(2), 137-161.

Portaria n. 378, de 9 de maio de 2016 (2016). Dispõe sobre a autorização de funcionamento de unidades dos Institutos Federais e atualiza a relação de unidades que integram a Rede Federal de Educação Profissional, Científica e Tecnológica. Diário Oficial da União (Seção 1).

Rosano-Peña, C., Albuquerque, P. H. M., Daher, C. E. (2012). Dinâmica da produtividade e eficiência dos gastos na educação dos municípios goianos. Revista de Administração Contemporânea, 16(6), 845-865.

Sarraes, C. (2014, junho 24). Greve de professores e servidores de institutos e universidades federais é mantida. Brasília: Agência Brasil, Recuperado de http://www.ebc.com.br/noticias/brasil/2014/06/greve-de-docentes-eservidores-de-institutos-e-universidades-federais-e;.

Santos Neto, D. N., Santos, E. M. S., Silva, I. C., França, I. C., Silva, L. M. (2019). A evasão de estudantes nos cursos técnicos da modalidade integrada no IFBA - Campus Jacobina. Ensino em Foco, 2(4), 37-48.

Schuster, H. A., Zonatto, V. (2017). Evidências da eficiência de gastos públicos em educação: análise da alocação dos recursos destinados ao ensino fundamental nos estados brasileiros. Contextus-Revista Contemporânea de Economia e Gestão, 15(2), 8-33.

Silva, G. M., Pereira, T. R. L., da Silva Dantas, M. G., Araújo, A. O. (2016). Análise da eficiência nos gastos públicos com Educação Fundamental nos Colégios Militares do Exército em 2014. Revista Evidenciação Contábil \& Finanças, 4(1), 50-64.

Zoghbi, A. C. P., Matos, E. H. C. D., Rocha, F. F., Arvate, P. R. (2009). Mensurando o desempenho e a eficiência dos gastos estaduais em educação fundamental e média. Estudos Econômicos (São Paulo), 39(4), 785-809. 